\title{
2D and 3D imaging of the metamorphic carbonates at Omalos plateau/polje, Crete, Greece by employing independent and joint inversion on resistivity and seismic data
}

Hamdan Hamdan ${ }^{1}$, Nikos Economou ${ }^{1}$, Giorgos Kritikakis ${ }^{1}$, Nikos Andronikidis ${ }^{1}$, Emmanuil Manoutsoglou ${ }^{2}$, Antonis Vafidis ${ }^{1}$, Pangratis Pangratis ${ }^{1}$, and Georgina Apostolidou ${ }^{1}$

\begin{abstract}
:
Hamdan H., Economou N., Kritikakis G., Andronikidis N., Manoutsoglou E., Vafidis A., Pangratis P. and Apostolidou G., 2012. 2D and 3D imaging of the metamorphic carbonates at Omalos plateau/polje, Crete, Greece by employing independent and joint inversion on resistivity and seismic data. International Jourmal of Speleology, 41(2), 199-209. Tampa, FL (USA). ISSN $0392-6672$. http://dx.doi.org/10.5038/1827-806X.41.2.7

A geophysical survey carried out at Omalos plateau in Chania, Western Crete, Greece employed seismic as well as electrical tomography methods in order to image karstic structures and the metamorphic carbonates (Tripali unit and Plattenkalk group) which are covered by post-Mesozoic deposits (terra rossa, clays, sands and gravels). The geoelectrical sections image the metamorphic carbonates which exhibit a highly irregular relief. At the central part of the plateau the thickness of post-Mesozoic deposits (terra rossa, clays, sands and gravels) ranges from 40-130 m. A 3D resistivity image was generated by inverting resistivity data collected on a grid to the south west at the Omalos plateau. The 3D resistivity image delineated a karstic structure at a depth of 25 to $55 \mathrm{~m}$. On the same grid the depth to the top of the karstified carbonates ranges from $25-70 \mathrm{~m}$. This is also verified on the resistivity sections and seismic velocity sections along lines 5 and 7 of the above mentioned grid which are derived from the cross-gradients joint inversion.
\end{abstract}

Keywords: karst; geophysics; electrical tomography; seismic tomography; joint inversion

Received 12 January 2012; Revised 27 February 2012; Accepted 22 March 2012

\section{INTRODUCTION}

Environmental and engineering investigations in karst terrains involve the use of geophysical and borehole information for the site characterization. Sinkholes are the major hazard when developing structures at sites where the bedrock consists of carbonate rocks (Zhou et al., 2008). Geophysical methods extrapolate the borehole information. Among them, electrical methods have become a valuable tool for subsurface investigation due to their low cost in combination with the effectiveness and quick interpretation (Zhou et al., 1999; Stepisnik \& Mihevc, 2008).

Since the 1920's electrical methods have been used for imaging the subsurface, mainly electrical sounding (VES). However, VES does not take into consideration the lateral geological heterogeneity and suffers from the ambiguities of a one dimen-

\footnotetext{
${ }^{1}$ Laboratory of Applied Geophysics, Department of Mineral Resources Engineering, Technical University of Crete, Polytechnioupolis, Chania, Greece (hamdan@mred.tuc.gr)

${ }^{2}$ Tectonic, Stratigraphy, Environmental geology lab, Department of Mineral Resources Engineering, Technical University of Crete, Polytechnioupolis, Chania, Greece
}

sional inversion. The evolution of two-dimensional inversion algorithms (Loke \& Barker, 1996; Tsourlos et al., 1998) increased inversion robustness by processing the sequential electrical soundings as resistivity sections. Meanwhile, the development of multi-electrode resistivity surveying instruments, which enabled automated data collection, made the electrical tomography method one of the most widely used geophysical methods for near-surface investigations. Currently, fast acquisition $3 \mathrm{D}$ data instruments and inversion algorithms (Papadopoulos et al., 2007) enhance the reliability of the method.

The Electrical Resistivity Tomography (ERT) method has been effectively used in bedrock investigations, soil and rock characterization, as well as in imaging voids and fractures in rocks (Seaton $\&$ Dean, 2004). The use of different electrode arrays over karstic formations was studied by Zhou et al. (2008). They concluded that the use of the dipole-dipole array is the most suitable method for assessing dolines or sinkholes in carbonate rocks. Hamdan \& Vafidis (2009) applied combined inversion of the resistivity data from both the WennerSchlumberger and dipole-dipole arrays for imaging karstic structures.

The difficulty in imaging karstic heterogeneities is usually handled by employing at least two geo- 


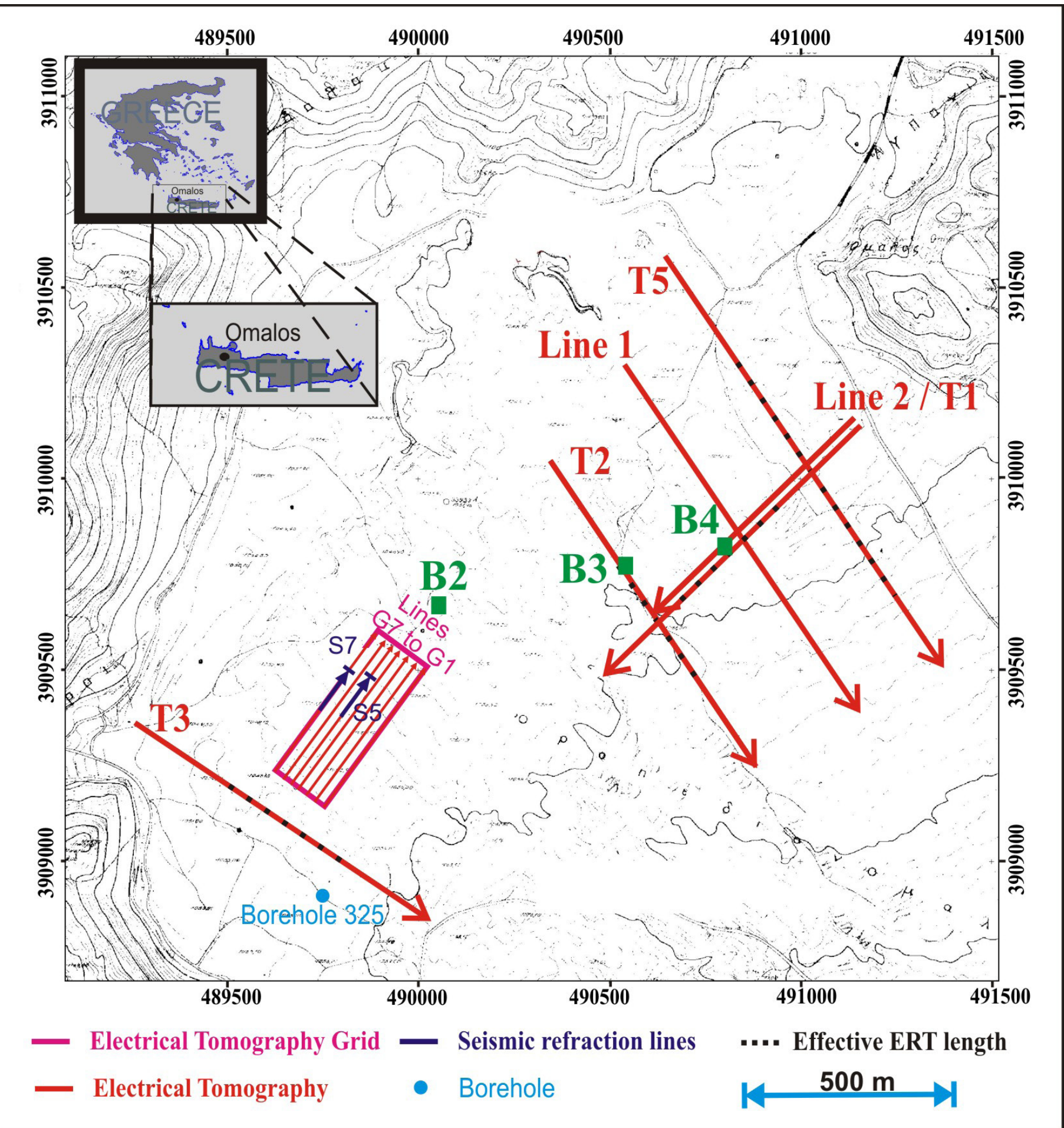

Fig. 1. Survey area on the Omalos plateau.

physical methods, such as microgravity, electrical methods and GPR (Sumanovac \& Weisser, 2001; Barbadello et al., 2002; Leucci, 2003; Vafidis et al., 2004; Elawadi et al., 2006; Hamdan et al., 2010). This integrated geophysical approach produces a more reliable subsurface image. However, the integrated interpretation of such plethora of geophysical data sets is very difficult and usually it is almost impossible to find a subsurface model which satisfies all the geophysical data sets.

Recently, joint inversion techniques have been developed to simultaneously invert data sets from two geophysical methods. Such techniques improve the subsurface model, which is consistent with all the available geophysical data. Initially, these methods focused on 1D inversion (Vozof \& Jupp, 1975; Lines et al., 1988; Dobroka et al., 1991; Hering et al., 1995) and later, on 2D inversion (Zhang \& Morgan, 1997; Gallardo \& Meju, 2003, 2004; FregosoBecerra \& Gallardo, 2007). The use of such techniques helps geophysical methods to overcome uncertainties, often encountered in imaging karstic structures.

In this study we present a geophysical survey carried out at the Omalos Plateau, Western Crete, Greece. This survey employed seismic refraction and geoelectrical methods. The later, consisted of 
Vertical Electrical Sounding (VES) and Electrical Resistivity Tomography (ERT). The objective of this survey was to image the complex tectonic structure of the active karstic system of the Omalos polje. Initially, VES and ERT were employed to estimate the maximum thickness of the recent deposits, which cover the karstified carbonates. Later, a grid of ERT lines, in combination with two seismic refraction lines was utilized to map the subsurface of an area dedicated to the construction of a reservoir. In this paper we examine the potential of ERT and seismic methods in delineating the relief of the karstic bedrock and present preliminary results from the joint inversion of seismic refraction and ERT data.

\section{GEOPHYSICAL SURVEYS}

The Omalos plateau is the largest active polje of Western Crete (Greece) and covers an area of approximately $6 \mathrm{~km}^{2}(3 \times 2 \mathrm{~km})$ (Fig. 1). The plateau consists of Post-Mesozoic sediments which lie on the "Trypali" metamorphic carbonates and the Plattenkalk carbonate group. The later formations are karstified at Omalos. The term karstification refers to geological processes mainly involving dissolution. These processes create unique morphological characteristics such as dolines, whose size varies from several meters to few hundreds of meters, or a polje which often results from more than one dolines or karstic structures. Electrical and seismic methods are very useful in delineating karstic structures such as these.

The geophysical survey at Omalos Plateau was conducted during four periods, from 2002 to 2009 (Vafidis et al., 2004; Alevras et al., 2007) by employing the VES, ERT and seismic refraction methods. The former method estimates the average thickness of the recent deposits, while the ERT and seismic refraction methods map the relief of the karstic carbonates. The data collected during the first (September 2002) and second (September 2003) periods include 3 VES (B2, B3 and B4 - Fig. 1), as well as 4 ERT lines (T1, T2, T3 and T5 - Fig. 1). The electrode spacing of the Wenner-Schlumberger array was set to $30 \mathrm{~m}$ for these ERT lines. In September 2008, we collected data along the lines 1 and 2 (Fig. 1), using the Wenner-Schlumberger array, $10 \mathrm{~m}$ electrode spacing and the roll along technique. During the last period (October 2009), an ERT grid (lines G1 - G7, Fig. 1) was scanned using also the WennerSchlumberger array and $10 \mathrm{~m}$ electrode spacing. The length of these ERT lines was $470 \mathrm{~m}$. During the same period, a seismic refraction survey was conducted along two lines (lines S5 and S7 - Fig. 1). Each seismic line consisted of two spreads having 5 $\mathrm{m}$ geophone interval and five shots per spread. The record length and the sampling interval were 512 $\mathrm{ms}$ and $0.125 \mathrm{~ms}$, respectively.

\section{Omalos polje}

The first phase of the geophysical survey at Omalos plateau (2002-2008) aimed at estimating the thickness of the recent deposits at the central parts of the polje (Fig. 1). Three (3) VES (B2, B3 and B4) and 6 ERT lines (T1, T2, T3, T5 and Lines 1 and 2) were surveyed (Fig. 1). The least squares approach was employed for the inversion of both 1D electric sounding (Ip2Win, Bobachow, 2002) and the 2D geoelectrical sections (RES2DINV, Loke \& Barker, 1996). The smoothness constraint regularizes the ill-posed 2D inversion method and provides smooth images of the subsurface.

ERT line T3, located to the southwest of the polje, is close to borehole 325 (Fig. 1). Borehole 325 drilled mainly Terra Rossa with gravels (55 m), clay with sand $(35 \mathrm{~m})$ and carbonates. ERT section T3 and Borehole 325, indicate that the top of the bedrock corresponds to approximately $300 \Omega \cdot \mathrm{m}$ (light green to yellow border line, Fig. 2). This information was used to calibrate the geoelectric sections in order to estimate the thickness of the recent deposits.

Three geoelectrical zones are delineated from B3 and B4 VES resistivity curves and ERT sections T2, T5, T1 and line 1 (Fig. 3). A shallow non-homogeneous zone with electrical resistivity values ranging from $300 \Omega \cdot \mathrm{m}$ to $3500 \Omega \cdot \mathrm{m}$, a lower resistivity (less than $200 \Omega \cdot \mathrm{m}$ ) zone and another high resistivity

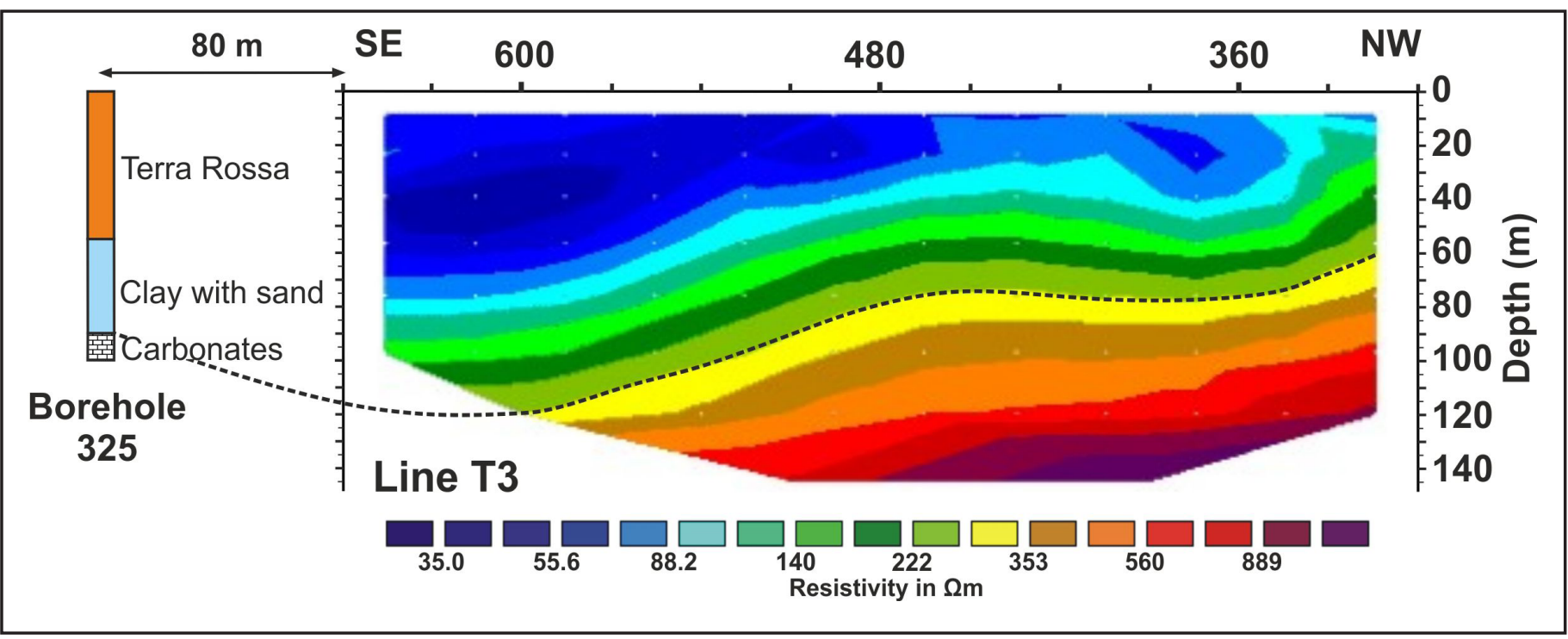

Fig. 2. Comparison of the electrical tomography section T3 with borehole 325 where the dotted line depicts $300 \Omega m$ contour. 
Hamdan Hamdan, Nikos Economou, Giorgos Kritikakis, Nikos Andronikidis, Emmanuil Manoutsoglou,
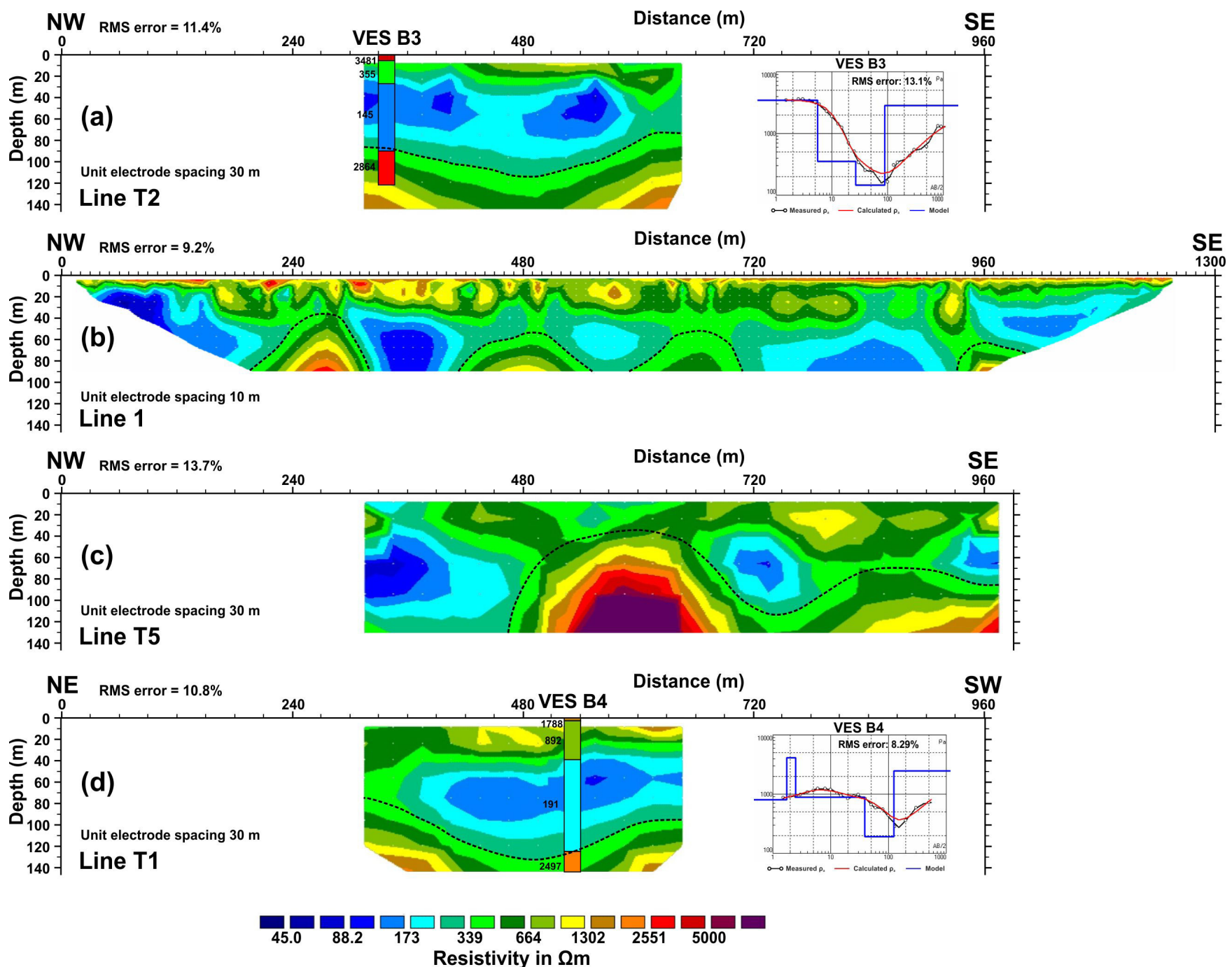

Fig. 3. (a) Comparison of the electrical tomography section T2 with the vertical electrical sounding B3; (b) The geoelectrical tomography section Line 2; (c) The geoelectrical tomography section T5 where the dotted line depicts the $300 \Omega \mathrm{m}$ contour and (d) Comparison of the electrical tomography section T1 with the vertical electrical sounding B4.

zone (more than $300 \Omega \cdot \mathrm{m}$ ). According to geological setting deduced from borehole 325 , the deeper layer is attributed to the carbonates, while the other two to the recent deposits (Post-Mesozoic).

Fig. 4 illustrates a $3 \mathrm{D}$ perspective view from the south of the ERT sections, where the carbonates (deeper high resistivity zone) exhibit a rough paleorelief. The thickness of post-Mesozoic deposits ranges from $40 \mathrm{~m}$ to more than $140 \mathrm{~m}$ (Fig. 3). Carbonates are expected at shallower depth along two ridges, with trend from S-SW to N-NE (purple curves on Fig. 4), delineating a valley. This valley is deeper at the northern part of the ERT line T5, since the bedrock is not present at depths less than 140 $\mathrm{m}$ at $420 \mathrm{~m}$ distance of line $\mathrm{T} 5$.

\section{Electrical Tomography Grid}

At the southwest part of Omalos plateau, an ERT grid (lines G1 - G7, Fig. 1) was surveyed (7 ERT parallel lines). According to the ERT sections G1 - G7 (Fig. 5), the depth to the bedrock (300 $\Omega \cdot \mathrm{m})$ ranges from $15 \mathrm{~m}$ to $70 \mathrm{~m}$. The relatively high RMS errors (10-15\%) are justified by the highly heterogeneous shallow layers.
A total of 3153 apparent resistivity datum points for 8 depth levels, were extracted from the parallel tomography lines and combined into a $7 \times 48$ grid before being processed using 3-D inversion (Res3Dinv). This inversion technique employed finite elements using 2256 cells for the calculation of the apparent resistivity data (forward problem) and the blocky (robust) inversion (Claerbout \& Muir, 1973). This gives reasonably accurate images of three-dimensional structures, bigger than $5 \times 5 \times 10 \mathrm{~m}$, enabling the 3D imaging of the subsurface using costeffective 2D electric tomography techniques (Dahlin \& Loke, 1997; Papadopoulos et al., 2006; Tsokas et al., 2008; Chang et al., 2011). The depth slices (Fig. 6) show a geoelectrical anomaly of low resistivity values in the northeastern part of the grid, at depths between 25 and 55 meters. This anomaly delineated by the 3D inversion of the resistivity data is attributed to a karstic structure (circled with the dotted ellipse).

On the same grid two seismic refraction lines were also surveyed (Fig. 1). The seismic velocity sections, generated using SeisImager software, indicate three distinct seismic layers (Fig. 7); a low velocity shal- 


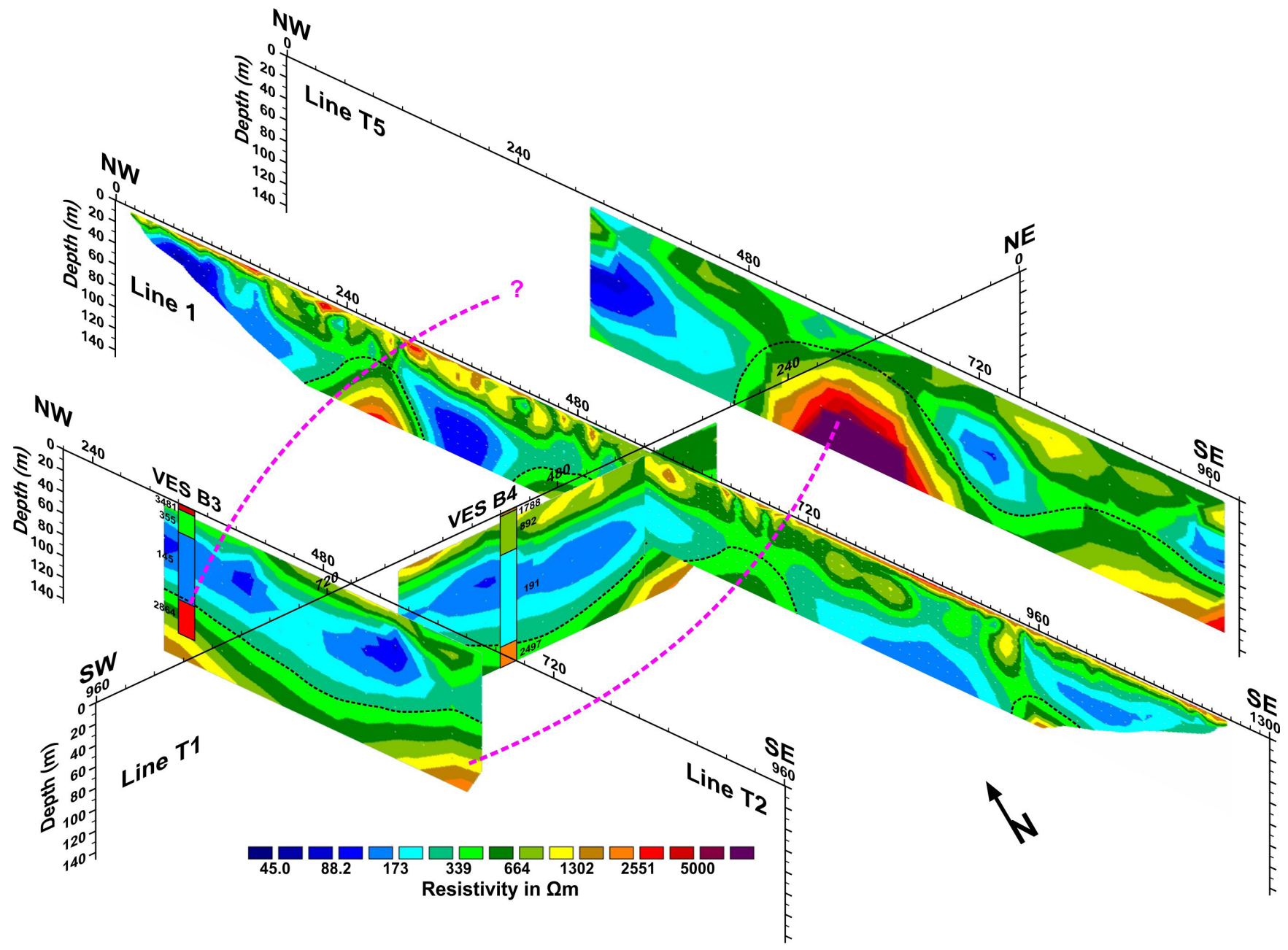

Fig. 4. 3D perspective view from the south of the ERT sections T1, T2, T5 and Line 2 where the deeper high resistivity zone is attributed to carbonates. Two ridges, with trend from S-SW to N-NE (purple curves), delineate a valley.

low layer $(800 \mathrm{~m} / \mathrm{s}$ and $5-7 \mathrm{~m}$ thickness, red color) overlies a layer with a seismic velocity of $1500 \mathrm{~m} / \mathrm{s}$ and thickness less than $15 \mathrm{~m}$ (yellow color). The deeper layer exhibits seismic velocity greater than $2100 \mathrm{~m} / \mathrm{s}$ (green and blue color). According to Fig. 8 the top of this higher velocity layer coincides with the electrical resistivity contour of $300 \Omega \cdot \mathrm{m}$. From the comparison of the resistivity image and the seismic velocity section one can conclude that the carbonates exhibit resistivity greater than $300 \Omega \cdot \mathrm{m}$ and seismic velocity greater than $2100 \mathrm{~m} / \mathrm{s}$. The shallower seismic and electric layers are attributed to the unsaturated recent deposits (Post-Mesozoic). This is in agreement with the B2 VES (northeast of the grid) which exhibits three geoelectrical layres. In particular the thickness of the recent deposits on the B2 VES resistivity curve is within the range of the thickness estimated on the grid (Fig. 9).

\section{Joint inversion of electrical and seismic tomog- raphy}

Joint inversion of electrical and seismic data was applied on lines G5/S5 and G7/S7. The goal was to achieve a unified geological model which will satisfy both seismic and electrical data sets. The crossgradients constraint was adopted, in order to jointly invert resistivity and seismic first arrival data (Gallardo \& Meju, 2003, 2004). The basic idea of this approach is to quantitatively estimate the structural similarity between resistivity and seismic velocity models, using the cross product of their gradients.

The cross-gradients joint inversion algorithm that was applied on these lines (Hamdan, 2010; Gallardo \& Meju, 2003, 2004), utilizes the gradients of both the seismic $\mathbf{t}\left(\mathbf{m}_{\mathbf{s}}\right)$ and resistivity $\mathbf{t}\left(\mathbf{m}_{\mathbf{r}}\right) \bmod$ els as a constraint inserted into the objective nonlinear least squares equation. In order to achieve structural similarity between both models the cross product of their gradients should be zeroed at all locations $\left(\mathrm{t}\left(\mathrm{m}_{\mathrm{r}}, \mathrm{m}_{\mathrm{s}}\right)=0\right)$. To satisfy this constraint, the gradient vectors must be parallel (same or opposite direction), at all locations where variation in the physical parameters (resistivity and velocity) occurs. This means that the boundaries of the geological layers, detected by both methods, are located at the same position.

To apply the joint inversion scheme on line 5 , the apparent resistivity data corresponding to the location of the seismic tomography were extracted keeping only the resistivity data between 230-340 m and depths between 0-50 m. The joint inversion for this line (Fig. 10) shows good structural similarity 
Hamdan Hamdan, Nikos Economou, Giorgos Kritikakis, Nikos Andronikidis, Emmanuil Manoutsoglou, Antonis Vafidis, Pangratis Pangratis, and Georgina Apostolidou
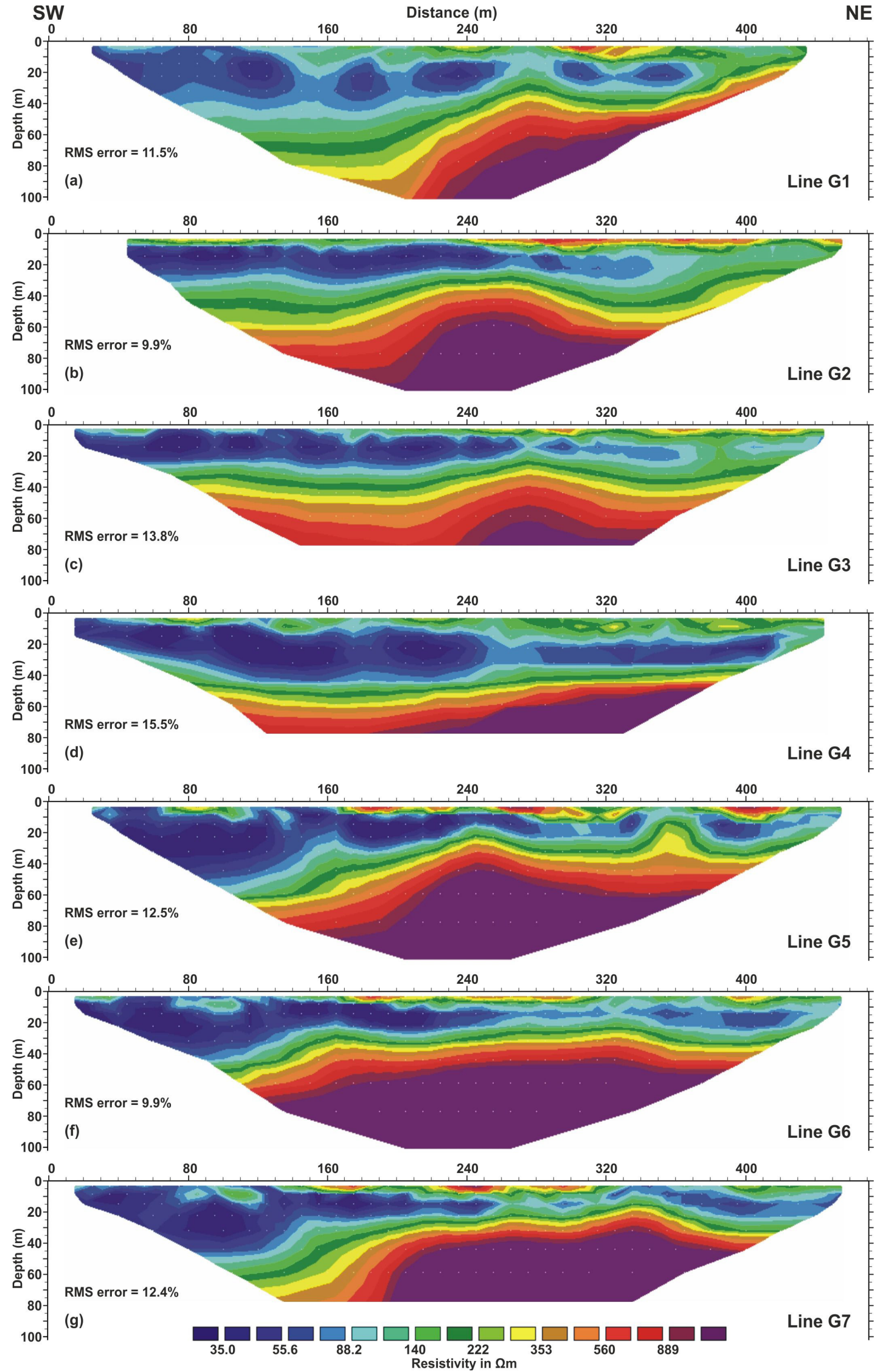

Fig. 5. Electrical tomography sections G1-G7. 

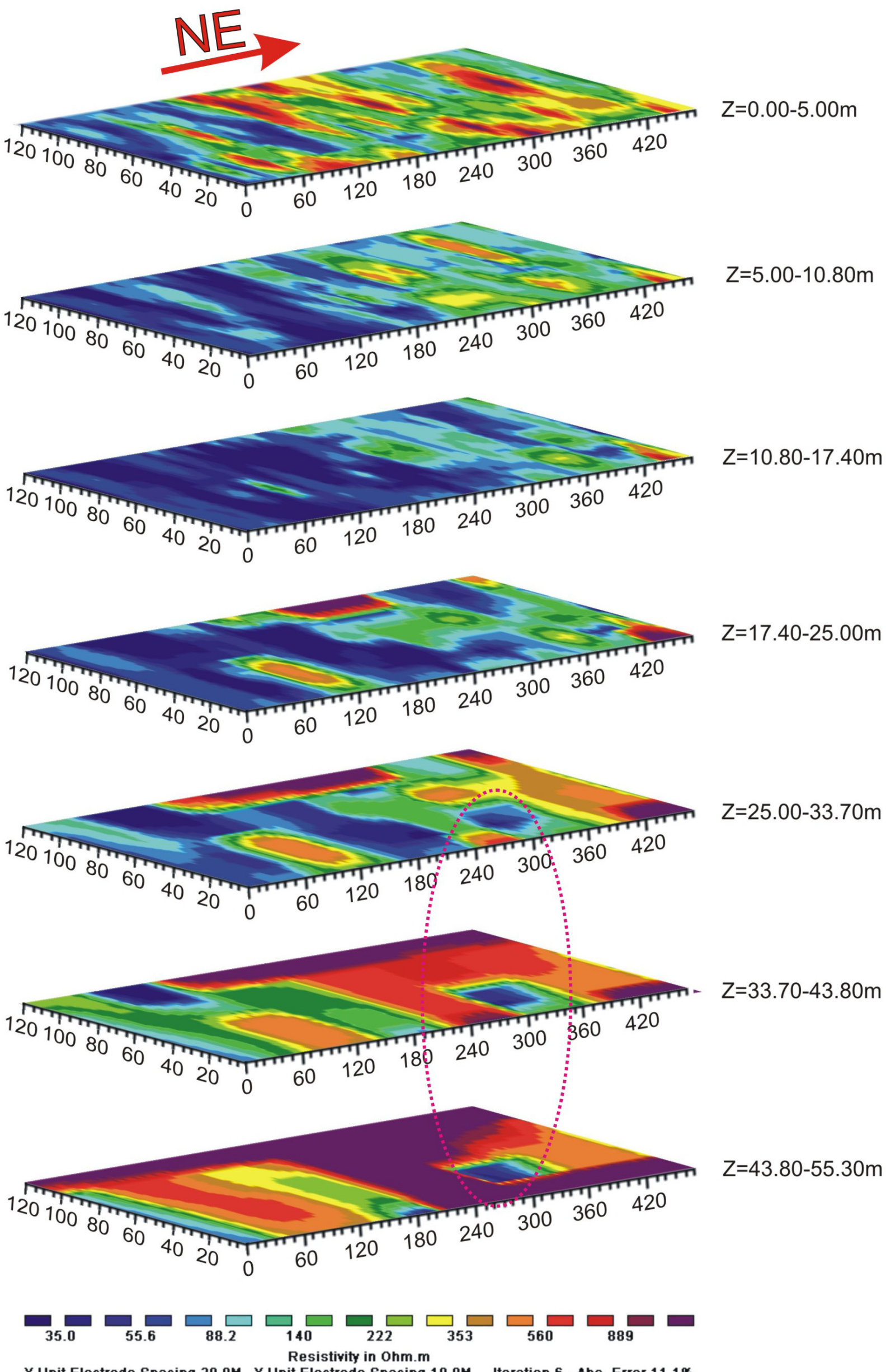

X Unit Electrode Spacing 20.0m. Y Unit Electrode Spacing 10.0M. Iteration 6 - Abs. Error 11.1\%

Fig. 6. Depth slices for the 3-D inversion of apparent resistivity data from the parallel tomography lines G1-G7. 



Fig. 7. Seismic velocity sections S5 and S7.

Distance $(\mathrm{m})$
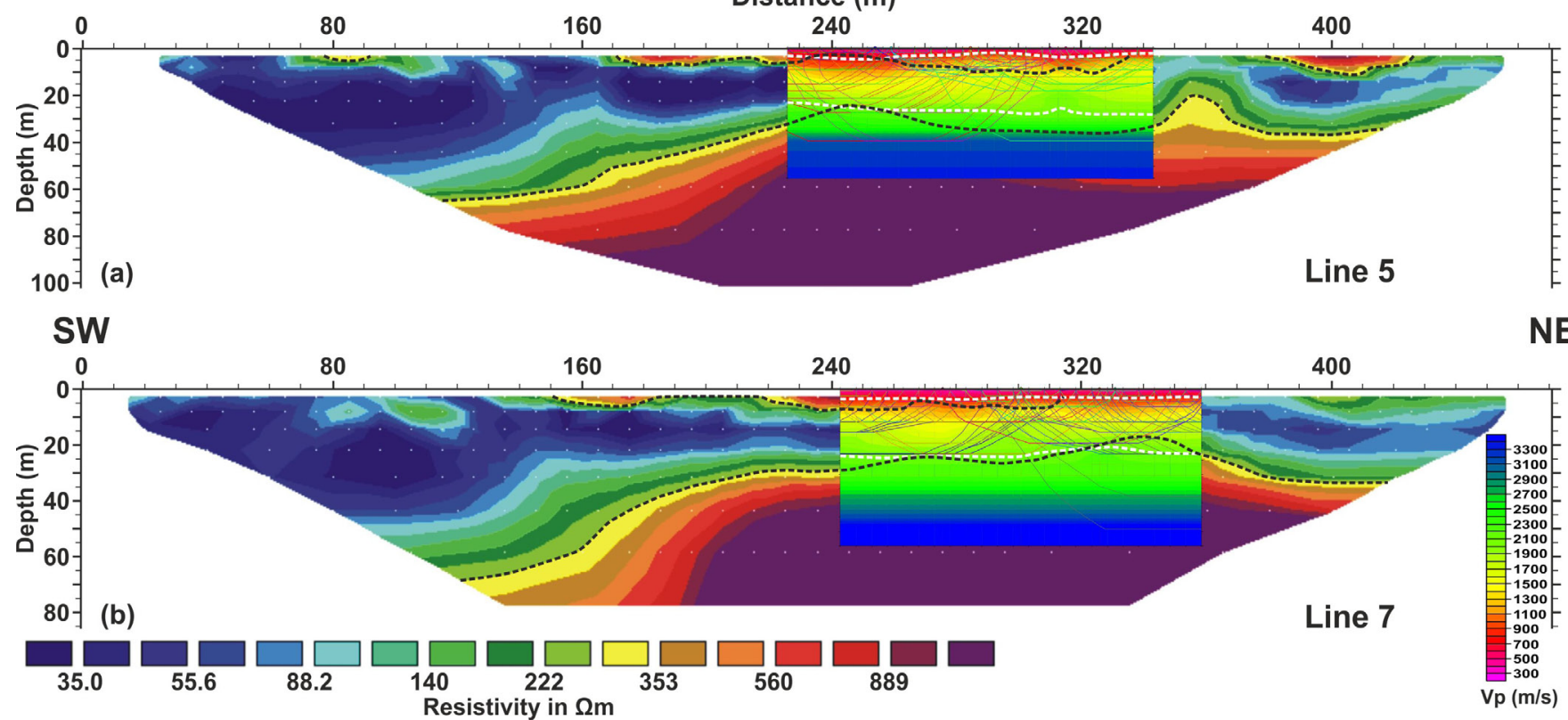

Fig. 8. (a) Seismic velocity section S5 on top of electrical tomography section G5 (b) Seismic velocity section S7 on top of electrical tomography section $\mathrm{G} 7$. The black dotted line depicts the $300 \Omega \mathrm{m}$ contour. 


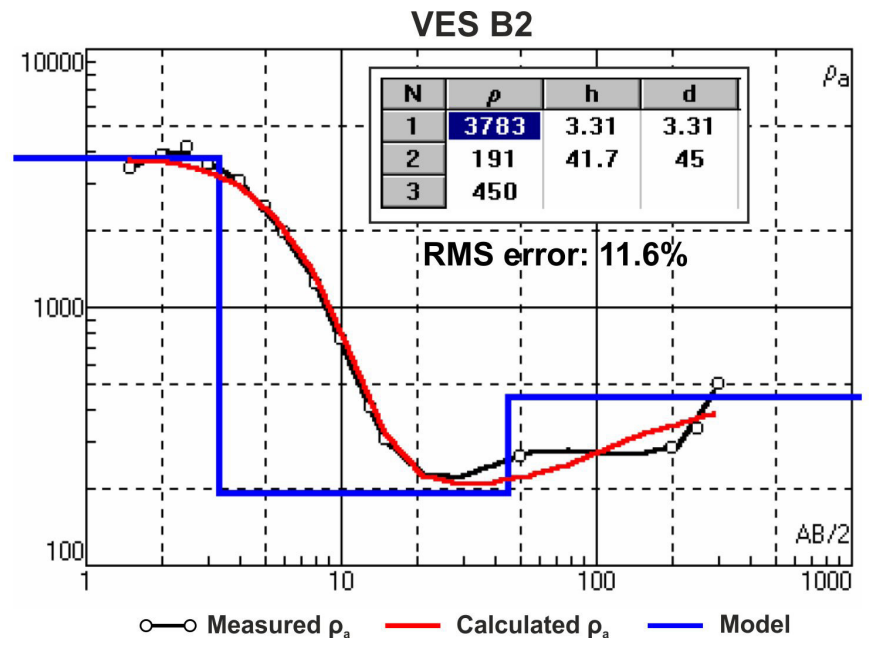

Fig. 9. Geoelectrical curve for VES B2 and its corresponding resistivity model.

between both sections, detecting the depth of the bedrock between 15-25 m, even though the seismic velocity decreases at depth greater than $25 \mathrm{~m}$, due to poor low ray coverage at these depths. The joint inversion for line 7 was less satisfactory. Although, the resistivity sections from the joint and from the 3D inversion are similar (Fig. 11).

\section{CONCLUSIONS}

At the Omalos plateau, seismic as well as electrical tomography methods imaged karstic structures of the metamorphic carbonates (Tripali unit and Plattenkalk group) which are covered by postMesozoic deposits. By combining the geoelectrical sections, we obtained a $3 \mathrm{D}$ perspective view of the metamorphic carbonates which exhibit a highly irregular relief in the central part of the plateau. Furthermore, the geoelectrical images have outlined deeper karstic structures on the Omalos plateau.

A 3D resistivity image was generated by inverting resistivity data collected on a grid to the south west at the Omalos plateau. The 3D resistivity image delineated a karstic structure at a depth of 25 to $55 \mathrm{~m}$. Based on borehole information we calibrated the resistivity sections of this grid and estimated the thickness of post-Mesozoic deposits which ranges from 25-70 m.

The seismic velocity sections image the bedrock along two selected lines of the above mentioned grid. The resistivity and seismic tomography images at the SW Omalos plateau area indicate that the bedrock exhibits a seismic velocity more than 2100 $\mathrm{m} / \mathrm{s}$ and resistivity more than $300 \Omega \mathrm{m}$.

On the same survey lines we jointly inverted travel time and apparent resistivity data by apply-

SW

(a)

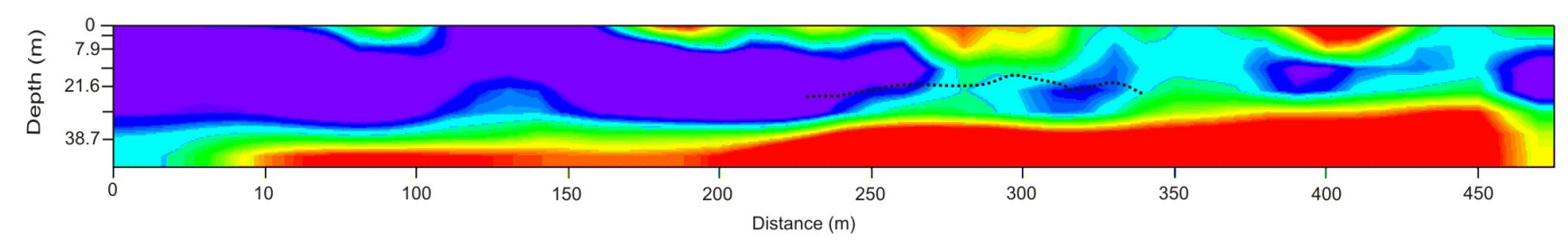

(b)

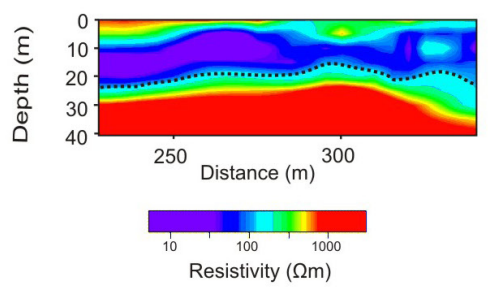

(c)

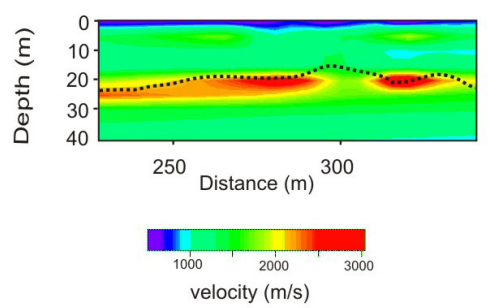

(d)



Fig. 10. (a) Electrical tomography section $(60-80 \mathrm{~m})$ extracted from the 3D inversion of the resistivity data along lines G1-G5. (b) Electrical tomography section and (c) seismic velocity section generated by cross-gradient inversion for line 5; (d) Electrical tomography section (80$100 \mathrm{~m}$ ) extracted from the 3D inversion of the resistivity data along lines G1-G5. The black dotted line depicts the $300 \Omega \mathrm{m}$ contour from the electrical joint inversion section. 


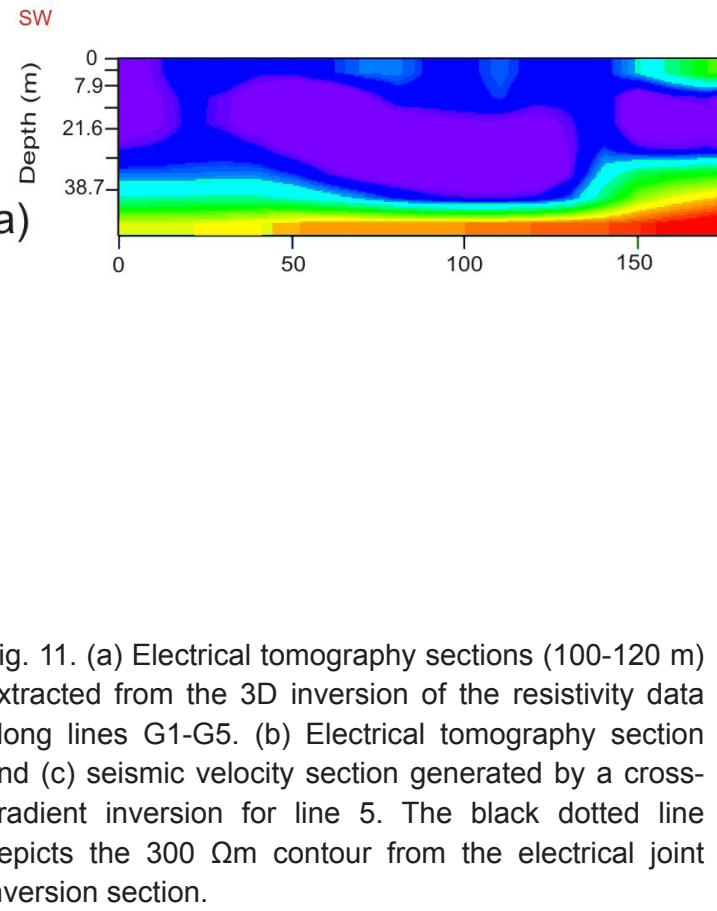

inversion section.

ing the cross gradients. The resistivity sections extracted from the joint inversion and from the 3D inversion are comparable regarding the top of the bedrock relief.

\section{REFERENCES}

Alevras A., Hamdan H., Vafidis A \& Manutsoglu E., 2007 - Geoelectrical Mapping of the Omalos Plateau/Polje, Chania, Western Crete, Greece. Proceedings of Near Surface 2007: the 13th European Meeting of Environmental and Engineering Geophysics of the Near Surface Geoscience Division of EAGE, 3-5 September, Istanbul, Turkey, 32.

Barbadello L., Bratus A., Yabar D.N., Paganini P. \& Palmieri F., 2002 - Integrated geophysical methods to define hypogenous karstic features. Atti del Museo Civico di Storia Naturale di Trieste, 49: $15-21$.

Bobachow A., 2002 - Ipi2win user's guide. Moscow State University.

Chang P., Chang S., Liu H. \& Wang S., 2011 - Using Integrated $2 D$ and $3 D$ Resistivity Imaging Methods for Illustrating the Mud-Fluid Conduits of the Wushanting Mud Volcanoes in Southwestern Taiwan. Terrestrial, Atmospheric and Oceanic Sciences, 22: 1-14.

ht t p: / / d x.d o i.org/10.3 $319 /$ TAO.2010.06.21.01(TT)

Claerbout F. \& Muir F., 1973 - Robust Modeling with Erratic Data. Geophysics, 38: 826-844. http://dx.doi.org/10.1190/1.1440378

Dahlin T. \& Loke M., 1997 - Quasi-3D resistivity imaging - Mapping of three dimensional structures using two dimensional DC resistivity techniques. Proceedings of the 3rd Meeting Environmental and Engineering Geophysics, Aarhus, Denmark, 8-11 September 1997, Extended Abstracts: 143-146. b)
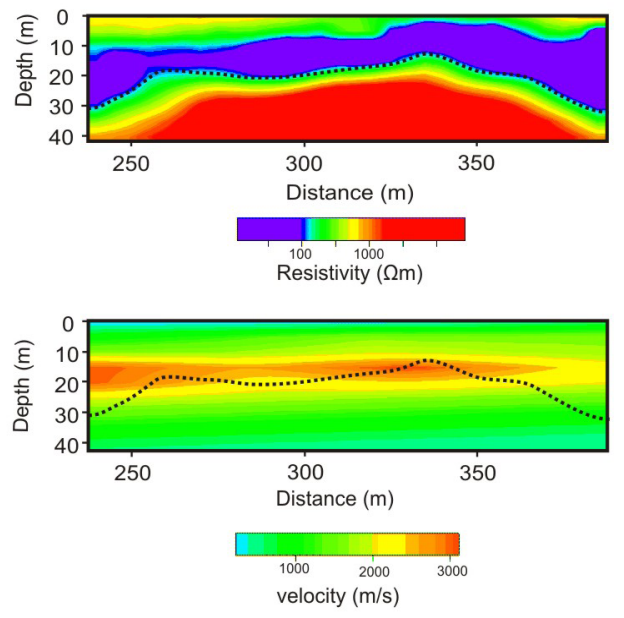

Dobroka M., Gyulai A., Ormos T., Csokas J. \& Dresen L., 1991 - Joint inversion of seismic and geoelectric data recorded in an underground coal mine. Geophysical prospecting, 39: 643-665.

http://dx.doi.org/10.1111/j.1365-2478.1991. tb00334.x

Fregoso-Becerra, E., \& Gallardo, L.A., 2007 - CrossGradient joint 3D inversion of Geophysical Data with Applications to Gravity and Magnetics. EGM 2007 International Workshop, Innovation in EM, Gravity and Magnetic methods: a new perspective for exploration, Italy.

Elawadi E., El-Qady G., Nigm A., Shaaban F. \& Ushijima K., 2006. - Integrated Geophysical survey for site investigation at a dwelling area, Egypt. Journal of Environmental \& Engineering Geophysics, 11: 249-259. http://dx.doi. org/10.2113/JEEG11.4.249

Gallardo L.A. \& Meju M.A., 2003 - Characterization of heterogeneous near-surface materials by joint $2 D$ inversion of $D C$ resistivity and seismic data. Geophysical Research Letters, 30: 1658-1661. http://dx.doi.org/10.1029/2003GL017370

Gallardo L.A. \& Meju M.A., 2004 - Joint two-dimensional DC resistivity and seismic travel time inversion with cross-gradients constrains. Journal of Geophysical Research, 109: 1-11. http://dx.doi.org/10.1029/2003JB002716

Haber E. \& Oldenburg D., 1997 - Joint inversion: a structural approach. Inverse problems, 13: 63-77. http://dx.doi.org/10.1088/0266$\underline{5611 / 13 / 1 / 006}$

Hamdan H. \& Vafidis A., 2009 - Inversion techniques to improve the resistivity images over karstic structures. Proceedings of the 15th European Meeting of Environmental and Engineering Geophysics, 3-5 September 2009 Dublin, Ireland, 2. 
Hamdan H., Kritikakis G., Andronikidis N., Economou N., Manoutsoglou E. \& Vafidis A., 2010 - Integrated geophysical methods for imaging saline karst aquifers: A case study of Stylos, Chania, Greece. Journal of the Balkan Geophysical Society, 13: 1-8.

Hamdan H., 2010 - Development of joint inversion techniques of geophysical data (Electrical resistivity and P-waves velocity) for the imaging of salt water intrusion in coastal areas. PhD Thesis, Technical University of Crete Chania, Greece. (in Greek).

Hering A., Misiek R., Gyulai A., Ormos T., Dobroka M. \& Dersen L., 1995 - A joint inversion algorithm to process geoelectrical and surface wave seismic data. Geophysical Prospecting, 43: 135-156. http://dx.doi.org/10.1111/j.1365-2478.1995. tb00128.x

Leucci G., 2003 - Evaluation of karstic cave stability using integrated geophysical methods. GeoActa, 2: 75-88.

Lines L.R., Schultz A.T. \& Treitel S., 1988 - Cooperative inversion of geophysical data. Geophysics, 53: 8-20. http://dx.doi.org/10.1190/1.1442403

Loke M. \& Barker R., 1996 - Rapid least-squares inversion of apparent resistivity pseudosections using a quasi-Newton method. Geophysical Prospecting, 44: 131-152.

http://dx.doi.org/10.1111/j.1365-2478.1996. tb00142.x

Papadopoulos N., Tsourlos P., Tsokas G \& Sarris A., 2006 - Two dimensional and Three-dimensional Resistivity Imaging in Archaeological Site Investigation, Archaeological Prospection, 13:163-181. http://dx.doi.org/10.1002/arp.276

Papadopoulos N.G., Tsourlos P., Tsokas G.N. \& Sarris A., 2007 - Efficient ERT measuring and inversion strategies for $3 D$ imaging of buried antiquities. Near Surface Geophysics, 5: 349-361.

Seaton W. \& Dean T., 2004 - Engineering site characterization with electrical resistivity surveys, No-DIG 2004, NASTT, New Orleans, Lousiana, March: 22-24.

Stepisnik U. \& Mihevc A., 2008 - Investigation of structure of various surface jarst formations in limestone and dolomite bedrock with application of the Electrical Resistivity Imaging. Acta Carsologica, 37: 133-140.
Sumanovac F. \& Weisser M., 2001 - Evaluation of resistivity and seismic methods for hydrogeologic mapping in karst terrains. Journal of Applied Geophysics, 33: 119-124.

Tsourlos P., Szymanski J. \& Tsokas G., 1998 A smoothness constraint algorithm for the fast 2-D inversion of DC resistivity data. Journal of the Balkan Geophysical Society, 1: 3-13.

Tsokas G., Tsourlos P. \& Papadopoulos N., 2008 - Electrical resistivity tomography: a flexible technique in solving problems of archaeological research. In: Piro S. \& Campana S. (Eds)., In Seeing the Unseen, Geophysics and Landscape Archaeology, Taylor \& Francis: 83-104.

Vafidis A., Manoutsoglou E., Andronikidis N., Hamdan H., Koukadaki M., Kritikakis G., Economou E. \& Spanoudakis N., 2004 - Geophysical survey at the Omalos Plateau, Chania, Crete. Proceedings of the 10th International Congress of the Hellenic Geological Society, 15-17 April 2004, Thessaloniki, Greece: 1204-1213.

Vozof K. \& Jupp D.B., 1975 - Joint inversion of geophysical data. Geophysical Journal of the Royal Astronomical Society, 42: 977-991. http://dx.doi.org/10.1111/j.1365-246X.1975. tb06462.x

Zhang J. \& Morgan F.D., 1997 - Joint seismic and electrical tomography. EEGS Symposium on Applications of Geophysics to Engineering and Environmental Problems. Keystone, Colorado, 391396. http://dx.doi.org/10.4133/1.2922412

Zhou WF., Beck BF. \& Stephenson BJ., 1999 - Defining the bedrock/ overburden boundary in covered karst terranes using dipole-dipole electrical resistivity tomography. In: Powers M.H., Ibrahim A.B. \& Cramer L. (Eds)., Proc Symp Application of Geophysics to Engineering and Environmental Problems, Oakland, California, 14-18 March 1999. Colorado: Environmental and Engineering Geophysical Society: 331-339.

Zhou W., Beck B. \& Adams A., 2008 - Effective electrode array in mapping karst hazards in electrical resistivity tomography. Environmental Geology, 42: 922-928. http:/ /dx.doi.org/10.1007/s00254-002-0594-Z 